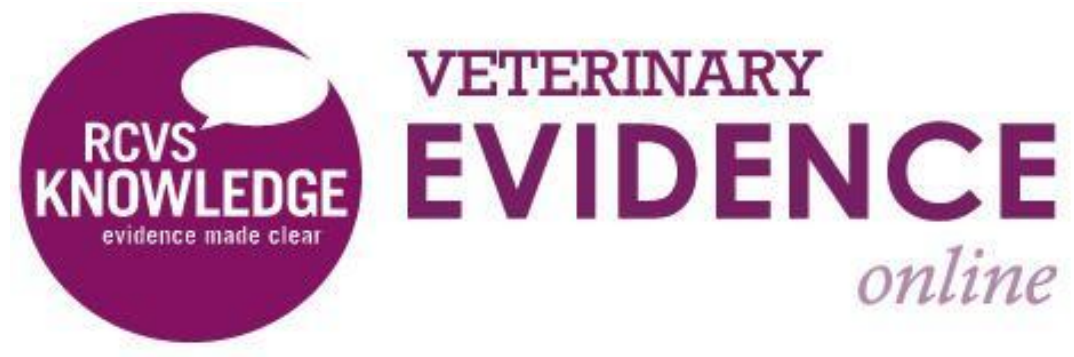

\title{
In Dogs with Periodontal Disease Is Feeding a Complete Raw Meat Diet More Effective Than a Complete Kibble 'Dental' Diet at Reducing Periodontal Disease?
}

\section{A Knowledge Summary by}

Nieky van Veggel MSc, CBiol, FHEA ${ }^{1^{*}}$

Matthew Armstrong BSc, (Hons), BVetMed, MRCVS ${ }^{2}$

\footnotetext{
${ }^{1}$ Writtle University College, Chelmsford, Essex, CM1 3RR, United Kingdom

${ }^{2}$ Natures Menu Ltd, Watton, Norfolk, IP25 6NG, United Kingdom

*Corresponding Author (Nieky.VanVeggel@writtle.ac.uk)
}

ISSN: 2396-9776

Published: 06 Apr 2017

in: Vol 2, Issue 2

DOI: http://dx.doi.org/10.18849/ve.v2i2.88

Reviewed by: Nicola Ackerman (BSc(Hons), RVN, CertSAN, CertVNECC, VTS(Nutr), A1 V1 MBVNA) and Sue Badger (MEd, Cert Ed, RVN)

Next Review Date: 06 Apr 2019 


\section{Clinical bottom line}

In light of the absence of evidence, vets and vet nurses should be cautious when recommending raw diets to support periodontal health and advise clients accordingly by relying on their clinical experience rather than the literature until more evidence is generated.

\section{Question}

In dogs with periodontal disease, is feeding a complete raw meat diet more effective than a complete kibble 'dental' diet at reducing periodontal disease?

\section{Clinical Scenario}

You are asked by a client for advice on improving the dental health of their dog after they read on the internet that periodontal disease negatively affects their dog's wellbeing. They read that raw feeding is better in improving the dental health of their dog than a commercial prescription kibble dental diet and are now asking you if there is evidence to support this.

\section{The Evidence}

No published research evidence currently exists regarding the influence of complete raw diets on dental health in dogs. During the literature search some expert opinion papers were found that made reference to dental health and raw feeding. The reference lists of these papers were scrutinised for relevant evidence, however none of the sources retrieved this way were relevant to the research question for this paper.

\section{Appraisal, application and reflection}

Although raw feeding in carnivores has been discussed for many years (see e.g. Fagan (1980) and Bond and Lindburg (1990)), it has become an increasingly popular concept in companion animals in recent years (Schlesinger and Joffe, 2011; Freeman et al., 2013) and owners regularly seek feeding advice from veterinarians. However, the evidence-base for raw feeding-related issues in dogs, and companion animals in general, is underdeveloped. The majority of research relating to raw feeding to date has focused on nutritional risk/benefit to the animal and public health and consumer safety.Schlesinger and Joffe (2011) argue that although some high level evidence based on mainly North American studies is available regarding the latter, the evidence base for the former is weak.

In all literature search strategies, the balance between sensitivity and precision of the literature search is key (O'Connor et al., 2014). Due to the nature of the evidence regarding raw feeding, the search strategy for this paper was deliberately on the sensitive side so that no potential relevant papers would be missed. As a result, the authors believe the outcome of this paper to be representative of the lack of research on raw feeds and feeding, rather than it being related to the specificity of the literature search strategy.

During the inclusion/exclusion stage of the literature review 18 unique records were excluded for reporting on complementary feeds rather than complete feeds. These records included both raw and non-raw feed types. This shows there is merit in a critical evaluation of the current literature for evidence regarding complementary raw feeds and dental health in dogs. In addition, as the current systematic scrutiny of 
existing knowledge clearly highlights a gap in the evidence, a strong justification for further research is present (Lund et al., 2016). The authors therefore recommend original research into dental health and complete raw feeding is undertaken.

\section{Methodology Section}

\begin{tabular}{|c|c|}
\hline \multicolumn{2}{|l|}{ Search Strategy } \\
\hline $\begin{array}{r}\text { Databases searched and dates } \\
\text { covered: }\end{array}$ & $\begin{array}{l}\text { CAB Abstracts (1973-2017) PubMed (1950-2017) - Veterinary } \\
\text { Science filter applied Web of Science (1970-2017) }\end{array}$ \\
\hline Search terms: & $\begin{array}{l}\text { (dog OR dogs OR canine OR canines OR bitch OR bitches) AND } \\
\text { (periodontal disease OR gingivitis OR gingiva OR tartar OR plaque } \\
\text { OR stomatitis OR periodontitis OR gum disease OR dental disease } \\
\text { OR calculus) AND (feed OR diet OR food OR pet food) }\end{array}$ \\
\hline Dates searches performed: & 3rd January 2017 \\
\hline
\end{tabular}

\section{Exclusion / Inclusion Criteria}

Inclusion and exclusion criteria were determined in advance of the search phase. Papers were initially screened by title and abstract and included for analysis if they met the inclusion criteria below. Where there was doubt, papers were included. Subsequently, full-text articles were obtained and a second inclusion/exclusion phase based on the criteria below was performed. Where there was doubt about the suitability of a full text paper, an independent party was consulted and a majority vote applied.

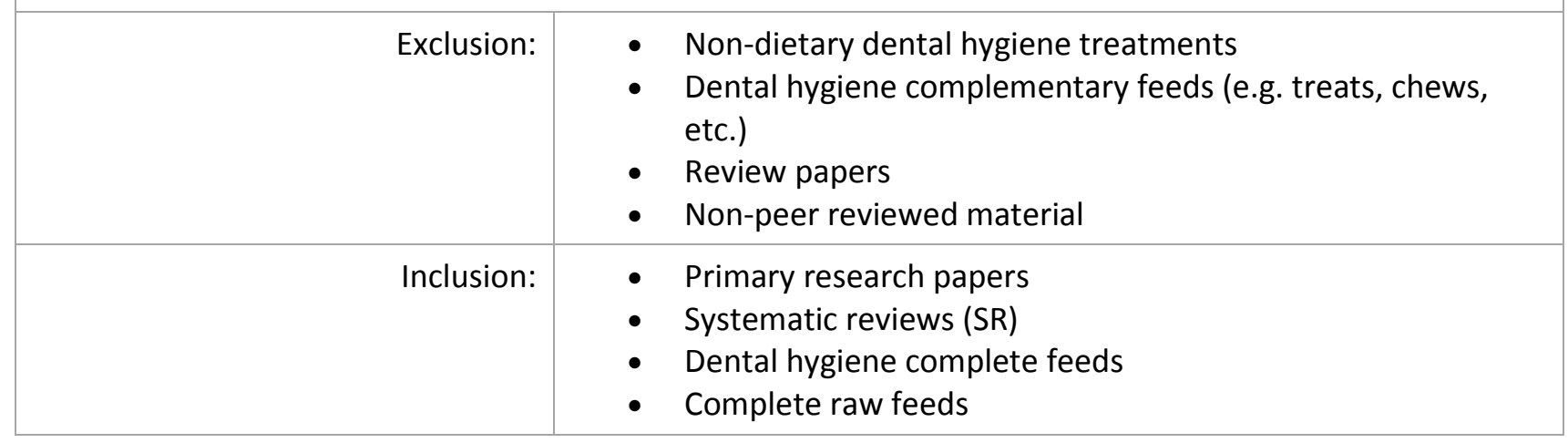

\begin{tabular}{|l|c|c|c|c|c|c|c|}
\hline \multicolumn{1}{|l|}{ Search Outcome } & $\begin{array}{l}\text { Number } \\
\text { of results }\end{array}$ & $\begin{array}{c}\text { Excluded }- \\
\text { not related } \\
\text { to PICO }\end{array}$ & $\begin{array}{c}\text { Excluded - } \\
\text { not primary } \\
\text { research/SR }\end{array}$ & $\begin{array}{c}\text { Excluded } \\
- \text { non- } \\
\text { dietary } \\
\text { treatment }\end{array}$ & $\begin{array}{c}\text { Excluded - } \\
\text { not } \\
\text { complete } \\
\text { feed }\end{array}$ & $\begin{array}{c}\text { Excluded } \\
\text { - kibble } \\
\text { feed } \\
\text { only }\end{array}$ & $\begin{array}{c}\text { Total } \\
\text { relevant } \\
\text { papers }\end{array}$ \\
\hline CAB Direct & 186 & 113 & 37 & 8 & 16 & 12 & 0 \\
\hline NCBI PubMed & 210 & 181 & 9 & 3 & 10 & 7 & 0 \\
\hline $\begin{array}{l}\text { Thomson } \\
\text { Reuters Web } \\
\text { of Science }\end{array}$ & 185 & 151 & 5 & 11 & 9 & 9 & 0 \\
\hline \\
\begin{tabular}{l} 
Total relevant papers when duplicates removed \\
\hline
\end{tabular}
\end{tabular}




\section{CONFLICT OF INTEREST}

Nieky Van Veggel declares no conflict of interest.

Matthew Armstrong declares the conflict of interest that he is an employee of Natures Menu, a producer of commercial raw pet food.

The authors would like to gratefully acknowledge Clare Boulton (RCVS Knowledge) for her help with finalising the search strategy and retrieving full-text papers.

\section{REFERENCES}

1. Bond, J. C. and Lindburg, D. G. (1990) Carcass Feeding of Captive Cheetahs (Acinonyx Jubatus): The Effects of a Naturalistic Feeding Program on Oral Health and Psychological Well-Being. Applied Animal Behaviour Science, 26 (4), pp. 373-382. https://doi.org/10.1016/0168-1591(90)90036-D

2. Fagan, D. A. (1980) Diet Consistency and Periodontal Disease in Exotic Carnivores. In: Proceedings of the American Association of Zoo Veterinarians, pp. 34-37. Available at http://citeseerx.ist.psu.edu/viewdoc/summary?doi=10.1.1.462.6411

3. Freeman, L. M., Chandler, M. L., Hamper, B. A., et al. (2013) Current Knowledge about the Risks and Benefits of Raw Meat-Based Diets for Dogs and Cats. Journal of the American Veterinary Medical Association, 243 (11), pp. 1549-1558. DOI: 2460/javma.243.11.1549

4. Lund, H. Brunnhuber, K. Juhl, C. et al. (2016) Towards Evidence Based Research. British Medical Journal, 355, October, i5440. DOI: 10.1136/bmj.i5440

5. O'Connor, A. M. Anderson, K. M. Goodell, C. K. et al. (2014) Conducting Systematic Reviews of Intervention Questions I: Writing the Review Protocol, Formulating the Question and Searching the Literature. Zoonoses and Public Health, 61, 28-38. DOI: 10.1111/zph.12125

6. Schlesinger, D. P. and Joffe, D. J. (2011) Raw food diets in companion animals: a critical review. The Canadian Veterinary Journal, 52 (1), pp. 50-54. Available at https://www.ncbi.nlm.nih.gov/pmc/articles/PMC3003575/ 


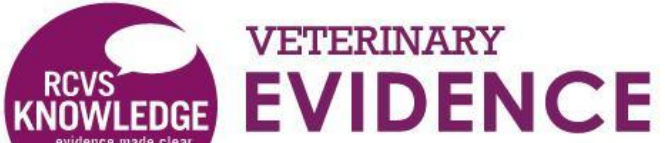 \\ ochese}

\section{Intellectual Property Rights}

Knowledge Summaries are a peer-reviewed article type which aims to answer a clinical question based on the best available current evidence. It does not override the responsibility

of the practitioner. Informed decisions should be made by considering such factors as individual clinical expertise and judgement along with patient's circumstances and owners' values. Knowledge Summaries are a resource to help inform and any opinions expressed within the Knowledge Summaries are the author's own and do not necessarily reflect the view of the RCVS Knowledge.

Authors of Knowledge Summaries submitted to RCVS Knowledge for publication will retain copyright in their work, but will be required to grant to RCVS Knowledge an exclusive license of the rights of copyright in the materials including but not limited to the right to publish, re-

publish, transmit, sell, distribute and otherwise use the materials in all languages and all media throughout the world, and to license or permit others to do so.

Authors will be required to complete a license for publication form, and will in return retain certain rights as detailed on the form.

Veterinary Evidence and EBVM Network are RCVS Knowledge initiatives. For more information please contact us at editor@veterinaryevidence.org

RCVS Knowledge is the independent charity associated with the Royal College of Veterinary Surgeons (RCVS). Our ambition is to become a global intermediary for evidence based veterinary knowledge by providing access to information

that is of immediate value to practicing veterinary professionals and directly contributes to evidence based clinical decision-making.

\section{www.veterinaryevidence.org}

RCVS Knowledge is a registered Charity No. 230886. Registered as a Company limited by guarantee in England and Wales No. 598443.

Registered Office:

Belgravia House

62-64 Horseferry Road

London SW1P 2AF 